\title{
O poder do periódico científico na construção da representação de pesquisa científica
}

\section{Resumo}

Objetivo: Conhecer a concepção de produção científica representada por meio da política da Revista Contabilidade e Finanças (RC\&F). Método: $\mathrm{O}$ estudo tem abordagem qualitativa e quantitativa. $\mathrm{O}$ trabalho descritivo foi desenvolvido por meio da análise de conteúdo de Bardin (2016) e do software UCINET 6. As inferências foram realizadas por meio da estatística básica (percentuais).

Resultados: Os editores associados da RC\&F são conselheiros de expressiva força ideológica no periódico. Os atributos "qualidade", "relevância" e "ineditismo" alicerçam a concepção de produção científica da RC\&F; tal concepção guarda influência da Universidade de São Paulo e de outras entidades técnicas, de educação e pesquisa nacionais e internacionais. No entanto, a subjetividade do significado desses atributos no texto da política editorial da RC\&F, ao se referir ao material publicável, contribui para a replicações lastreadas nos textos disseminado por esse periódico - podendo se tornar fator crítico para a inovação e para o desenvolvimento da cultura escrita da área. Contribuições: Os atributos norteadores da concepção de ciência, veiculada pela RC\&F, podem gerar ruídos de comunicação por causa da subjetividade que expressam, fato que pode acarretar em reprodução de temáticas, metodologias e teorias em virtude da busca um modelo de produção científica "relevante", apesar da política editorial expressar a ideologia do ineditismo e da "pluralidade ontológica e epistemológica”. A investigação realizada ratifica o poder do periódico ao conferir autoridade cientifica a estudiosos que, conforme a TRS, criam parâmetros e sistemas de valores que são propagados do universo reificado para o universo consensual. Palavras-chave: Periódico contábil; representações sociais; produção científica.

\author{
Iracema Raimunda Brito Neves \\ Aragão \\ https://orcid.org./0000-0002-7419-2127 \\ Doutora em Controladoria e Contabilidade \\ pela Universidade de São Paulo (USP) \\ e Professora Adjunta na UEFS/FAT e \\ Coordenadora Colegiado de Ciências \\ Contábeis na Universidade Estadual de \\ Feira de Santana (UEFS) e Faculdade Anísio \\ Teixeira (FAT). Contato: Av. Transnordestina \\ $\mathrm{s} / \mathrm{n}^{0}$. Novo Horizonte. Feira de Santana (BA). \\ CEP: 44036-900 \\ E-mail: irbn31@yahoo.com.br
}

\section{Gilberto de Andrade Martins} https://orcid.org./0000-0001-5144-5286 Doutor em Administraçãa de Empresas pela Universidade de São Paulo (USP) e Livre Docente e Professor Titular na Universidade de São Paulo (USP). Contato: Av. Prof. Luciano Gualberto, 908. Butantã. São Paulo (SP).

CEP: 05508-010

E-mail: martins@usp.br

\section{Valdir Heitor Barzotto}

https://orcid.org./ 0000-0003-1564-9550

Doutor em Linguística pela Universidade Estadual de Campinas (Unicamp) e Livre Docente e Professor Adjunto na Universidade de São Paulo (USP). Contato: Av. da Universidade, 308. Butantã. São Paulo (SP). CEP: 05508-040

E-mail: barzotto@usp.br 


\section{Introdução}

Os estudos divulgados por meio dos periódicos científicos são capazes de persuadir e formar opinião. Tal fato decorre do pressuposto de cientificidade que esses estudos possuem.

A ciência influência a humanidade, criando e alterando convicções, bem como ampliando de maneira contínua as fronteiras do conhecimento (Targino, 2000). Neste sentido, pode-se afirmar que o periódico científico introduz e/ou estabelece ideologias resultantes da concepção de mundo dos sujeitos que produzem pesquisas e as disseminam no formato de artigo. A publicação do artigo ratifica que ele está em consonância com a concepção de relevância e cientificidade do conselho editorial de um periódico.

Nesta investigação, concebe-se o artigo publicado e o editorial do periódico científico como formadores de representação social por fazerem emergir a concepção de mundo de sujeitos enquanto pesquisadores - concepção constituída por experiências e relações socialmente estabelecidas. Trata-se da difusão do pensamento científico como gerador de senso comum conforme apregoa a Teoria das Representações Sociais (TRS), de Moscovici (1978/1961). Trata-se de conhecimento construído por meio da compreensão alcançada por um indivíduo, a qual se assemelha a pronunciamentos de grupos de indivíduos, evidenciando que eles pensam da mesma forma sobre o mesmo assunto. Assim, a concepção de produção científica evidenciada no discurso da política editorial e do artigo publicado origina mainstream - ainda que descartada a possibilidade de "receita" para garantir a validação da qualidade e/ou relevância do material publicável.

Ao buscar um periódico científico para veicular os resultados da sua investigação, o autor torna pública a sua aderência à forma de conceber e construir ciência manifestada pela política editorial desse periódico. Tal cumplicidade ideológica é um dos elementos que assegura a submissão e oportuniza o início do processo avaliativo que pode culminar na aprovação e, conseguinte, publicação do texto científico. Segundo Frezatti, Nascimento e Junqueira $(2009$, p. 7$)$, “... o sistema de publicação funciona dentro dos paradigmas estabelecidos pelos periódicos, o que torna a inovação um risco quando o construto teórico e metodológico fugir do mainstream estabelecido".

Sem perder de vista a existência de linhas de pesquisas e áreas de interesse de um periódico, a afirmação de Frezatti, Nascimento e Junqueira (2009) permite afirmar que as normas e as perspectivas estabelecidas por um periódico tanto podem favorecer a um dado universo de pesquisa quanto podem limitar o avanço do conhecimento e exploração pesquisas emergentes - independente da sua qualidade e significado social.

O periódico científico é preferencial veículo de disseminação da ciência, figurando uma rede intelectual de diálogo entre cientistas e pesquisadores (Meadows, 1999; Gruszynski, Colin \& Castedo, 2008; Rodrigues, Quartiero \& Neubert, 2015). Conscientes da relevância do periódico científico como veículo de disseminação do conhecimento, bem como de que o mesmo está impregnado por ideologias que constituem representação social do pensamento de intelectuais de determinada área de conhecimento, objetivou-se conhecer a concepção de produção científica representada por meio da política da Revista Contabilidade e Finanças (RC\&F). Para o alcance deste objetivo geral, têm-se como específicos: verificar a composição da equipe editorial da RC\&F; identificar as entidades das quais os conselheiros da RC\&F fazem, ou fizeram, parte e interpretar a tessitura do discurso que compõe a sua política editorial.

Trata-se de uma investigação descritiva de abordagem fundamentalmente qualitativa, alicerçada na análise de conteúdo de Bardin (2016). Usou-se, especificamente, a técnica de análise temática ou categorial, a qual se fundamenta na descoberta de núcleos de sentidos que compõem a comunicação. Essa técnica, cuja frequência de aparição do termo possui representatividade para o objetivo da pesquisa, é composta de três etapas: pré-análise, exploração do material e tratamento dos resultados obtidos - tais etapas são pormenorizadas na seção "Metodologia". A abordagem quantitativa se deu pela necessidade de análise composição da equipe editorial e a identificação das entidades das quais essa equipe fez/faz parte. A descrição da equipe editorial da RC\&F se deu por meio da obtenção de informações fundamentadas no currículo dos seus membros (lattes para brasileiros e vitae para estrangeiros). Após obtenção das informações descritivas, foram constituídas redes, plotadas pelo software UCINET 6, cuja interpretação se deu por meio de valores relativos. 
Esta pesquisa se justifica pela relevância do periódico na disseminação do conhecimento científico para a comunidade científica global e à sociedade contemporânea, bem como por ser o periódico científico elemento decisivo no processo de formação ideológica. Ademais, tem-se como corpus de estudo a política editorial da RC\&F - periódico que, potencialmente, exerce significativa influência ideológica por possuir o maior fator impacto da área contábil no Brasil. Tal afirmação se sustenta em estudo sobre a ressonância da pesquisa contábil realizado por Aragão, Oliveira e Lima (2013). Ademais, a RC\&F é vinculada ao mais antigo Programa de Pós-Graduação de Controladoria e Contabilidade (PGCC) do país - segundo Cunha, Cornachione Júnior e Martins (2008) criado em 1978 - o que lhe confere reconhecimento nacional e internacional pela tradição em matéria de pesquisa na área contábil.

Os resultados evidenciam que os mecanismos cognitivos envolvidos no processo de representação do discurso científico, da concepção de qualidade e de estrutura da produção científica da RC\&F decorrem, fundamentalmente, da comunidade FEA/USP - 53\% dos membros do conselho editorial desse periódico fazem dela. Tal fato, atrelado ao significativo Fator de Impacto desse periódico, o torna instrumento de poder e autoridade científica com capacidade de influenciar, dialeticamente, o saber cotidiano. Segundo a teoria das Representações Sociais (TRS) a interação entre o universo reificado e o universo consensual geram as práticas que são levadas a grupos sociais, constituindo o sistema de valores dos sujeitos que os compõem. Todavia, a subjetividade de termos como "qualidade" e "relevância", ao tratar do material publicável, contribui para a replicações lastreadas nos textos disseminado por esse periódico - podendo se tornar fator crítico para a inovação e para o desenvolvimento da cultura escrita da área.

Este artigo está dividido em cinco seções. A primeira é esta a Introdução que apresenta a problemática, a justificativa e os objetivos do estudo. A segunda contém o referencial teórico explorado, o qual apresenta discussão sobre a teoria das Representações Sociais e o pensamento científico, sobre o periódico científico como veiculo de comunicação e poder, bem como discute sobre a composição da equipe editorial e sua função na elaboração da política editorial de um periódico científico. Na terceira têm-se a metodologia e informações sobre o objeto de estudo; na quarta a análise de resultados; e na quinta, última seção, as conclusões.

\section{A Teoria das Representações Sociais e o Pensamento Científico}

O pensamento de um grupo sobre o "rigor científico" representa a forma que este grupo adota para sistematizar a ciência em um tempo histórico, ou seja, constitui uma formação ideológica que se propaga inter e intra grupos. Wurman (1992) afirma que o individuo é resultado do que lê e é julgado pela informação que utiliza, visto que essa informação ingerida molda a sua personalidade, contribui para as ideias formuladas e constrói a sua visão de mundo.

Para Santos Filho (2016, p. 108), "as ideias científicas frequentemente camuflam suas origens extracientíficas, dissimulação geralmente característica em se tratando de ideologias". Por sua vez, Targino (2010) afirma que a ciência recebe da sociedade impactos que a (re)orientam de maneira dinâmica e interativa por meio de confrontos e cooperação. A relação entre o conhecimento científico e o senso comum, explanada por esses autores, é lastro de discussão da Teoria das Reapresentações Sociais (TRS), de Moscovici (1978/1961). Nessa teoria, o científico e o senso comum se recorrem mutuamente elaborando a práticas sociais. Moscovici (2001) esclarece que as representações sociais emergem do discurso científico, do qual o senso comum se apropria por meio de indivíduos que demonstram interesse pela temática e a levam para o grupo social que integram.

Moscovici não elaborou um conceito ao longo do desenvolvimento da sua teoria, suas obras apresentam uma série de apontamentos sobre elementos que caracterizam as representações sociais (Sá, 1993). Essas representações sociais são entidades intangíveis que “(...) se cruzam e se cristalizam continuamente através da fala, do gesto, do encontro no universo cotidiano. A maioria das relações sociais efetuadas, os objetos produzidos e consumidos, comunicações trocadas estão impregnada delas" (Moscovici, 2012/1989). 
O conceito de Representações Sociais é elaborado por Jodelet (2001, p. 22) que o considera como "forma de conhecimento, socialmente elaborada e partilhada, com um objetivo prático, e que contribui para a construção da realidade a um conjunto social" - nesta investigação, entende-se que a política editorial da RC\&F origina conhecimento sobre a concepção de pesquisa, propagada na área de conhecimento da Contabilidade e constituindo-se como representação social.

Os mecanismos cognitivos envolvidos no processo de representação do discurso científico por uma comunidade específica foram indagados por Moscovici, que o posicionou dialeticamente como reflexo do saber cotidiano - um tipo de conhecimento representado em grupo que acompanha o processo de mudança e transformação de saberes (Paula \& Kodato, 2016; Jodelet, 1986). Ainda sobre o conhecimento científico, Lane (1984, p. 15) apresenta crítica sobre a ideia de neutralidade da ciência na tendência da psicologia social e alerta que "se o positivismo, ao enfrentar a contradição entre objetividade e subjetividade, perdeu o ser humano, produto e produtor da história, se tornou necessário recuperar o subjetivismo".

A construção da Representação Social (RS) se dá pela interação entre o universo reificado e universo consensual: no primeiro, encontram-se a ciência e suas teorias (pensamento erudito, objetividade e rigor metodológico); no segundo, está a interação social - conversação geradora de teorias do senso comum (Sá, 1993). O universo reificado é ambiente em que o universo consensual encontra elementos para transformar o científico em senso comum - esse entrelaçamento entre o erudito e a conversação, atividade cognitiva, se dá por meio de dois processos da TRS: objetivação e ancoragem.

A objetivação e a ancoragem são processos que acontecem de maneira concomitante. No processo de objetivação, o conceito abstrato é incorporado à realidade e se materializa, transpondo os limites do pensamento como parte do mundo real (Moscovici, 2012/1989). Segundo o mesmo autor o processo de ancoragem se fundamenta na classificação de fatos, pessoas e objetos, categorizando-os a partir de concepções e conceitos prévios - momento em que ocorre a nomeação ou renomeação deles, integrando os sistemas de valores dos sujeitos.

Silva (2017, p. 41) assegura que a partir do "movimento entre o saber erudito e saber do senso comum, é que as representações sociais se apresentam como campo relevante para compreensão da elaboração desses saberes no seio das interações sociais". Esta pesquisa apropriou-se da teoria das Representações Sociais como articuladora entre autor(a), texto, leitor(a) e sociedade para a construção de uma concepção e prática de produção científica no formato de artigo por meio de um dos fatores imprescindíveis na elaboração das representações sociais - a comunicação intra e intergrupos.

\subsection{O periódico científico como veículo de comunicação e poder}

A motivação precípua de uma investigação científica decorre do interesse pessoal do pesquisador. Esse interesse inicial é natural e esperado, dado que se origina dos valores culturais, do conhecimento acumulado e das relações sociais estabelecidas por quem investiga - base de uma concepção de mundo (ideologia) fundada em contexto social e histórico. Conforme Meadows (1999) há dois grupos de motivações para a pesquisa: grupo de natureza psicológica - ligado ao comportamento e aos anseios do pesquisador - e de natureza social - que decorre da influência dos grupos sociais com os quais o pesquisador interage.

Pode-se afirmar que a motivação de natureza psicológica é elemento propulsor, mas não é justificativa para considerar a relevância da pesquisa ou a criação de um periódico científico. Logo, a autoridade científica não pode negligenciar a inter-relação entre a ciência e sociedade, dado que a primeira não é corpus autônomo. Segundo Targino (2016), as mudanças sociais impactam a ciência, ou pelo menos deveriam impactar, dado que a ciência é orientada a perseguir novos caminhos que lhe possibilite responder a demandas emergentes e suprir prioridades recentes - a ciência precisa ser útil socialmente.

Targino (2010) aponta que a demarcação científica nem sempre segue a parâmetros de universalidade em função de critérios externos, não explicitados, que influenciam a avaliação, a exemplo da ênfase na opinião dominante de pesquisadores de determinada área por autoridade científica - os artigos publi- 
cados em periódicos evidenciam e disseminam tal opinião dominante. Rodrigues et al. (2015) ressalta que os periódicos científicos se diferenciam em formato, composição, regularidade e assuntos tratados, mas têm como objetivo comum difundir as produções realizadas nas áreas de conhecimento.

De acordo com Gomes (2010), os periódicos científicos ocupam lugar de destaque na troca entre as comunidades científicas e acadêmicas, bem como entre estas e a sociedade. Da criação à proliferação, como veículo de comunicação dos resultados de estudos científicos em diversas áreas do saber, tais periódicos têm servido como instrumentos de mudanças políticas e de alterações na própria estrutura interna dessas comunidades - tornaram-se instrumentos de concessão de autoridade científica. Castedo e Gruszynski (2011) afirmam que a comunicação científica veiculada por meio de periódicos é um dos principais meios para conferir visibilidade a investigadores, por meio da acumulação de capital científico.

Todavia, não se pode perder de vista que o contexto contemporâneo da pesquisa científica brasileira tem sido marcado por uma série de cobranças em torno do acadêmico/pesquisador/cientista a fim de que divulgue os resultados de suas investigações, assegurando a retroalimentação do ciclo de comunicação científica e fechando o ciclo da dívida com a sociedade (Targino, 2010 e Targino, 2016) - fato salutar ao considerar a pesquisa como devolutiva social e meio profícuo de levar um país ao desenvolvimento. Todavia, a mesma autora nos chama atenção ao fato de que a pressão por produção científica acelerada, requerida por administradores e agências de fomento nacionais e internacionais, antes mesmo de consolidar pressupostos e teorias inerentes à investigação, tem contribuído para disseminação de textos inconsistentes, superficiais e fragmentados.

A fragilidade dos textos científicos compromete o desenvolvimento da cultura escrita da área e torna-se fato perigoso visto que, para além de ser veículo de comunicação e disseminação do conhecimento produzido em determinadas áreas do saber, o periódico científico se tornou instrumento de poder e a autoridade nas relações estabelecidas, triangularmente, entre a sociedade científica, a comunidade acadêmica e a sociedade em geral. O poder e a autoridade de um periódico decorrem da capacidade de argumentação e persuasão do discurso contido no texto da sua política editorial e, por conseguinte, nos textos publicados. Tais textos refletem a concepção de mundo e a forma de conceber ciência dominante no periódico, a qual é perpetuada entre seus pares e constroem a tessitura social - uma das maneiras de introduzir e estabelecer ideologias emergentes, principalmente, no que se refere às temáticas de interesse e abordagem de pesquisa.

A NBR 6021 (2003) esclarece que o conselho editorial do periódico é constituído por um grupo de pessoas que estabelece o perfil político-filosófico dele e que cabe à comissão científica (técnica ou editorial) a responsabilidade selecionar textos a serem publicados que se enquadrem na política editorial estabelecida pelo conselho. Autores como Belkin (1980), Fiorin (1993), Morin (2005) e Modesto (2014), discutem sobre a intencionalidade do texto; a formação ideológica presente em produções insuspeitáveis - a exemplo da ciência e dos meios de comunicação - além do poder de dominação dos textos ao disseminar informação. Aragão (2016) explana, a partir da análise de um corpus em tese de doutorado, que os textos científicos espelham posicionamentos solidificados, ou alterados, em função das relações estabelecidas socialmente.

É o periódico científico lugar de veiculação de um discurso prescritivo, uma prescrição materializada nas “.... opções que resultam em escolhas do que se diz e do que não se diz, do que se publica e do que não se publica..." (Cordeiro, 2008, p. 1). Essa prescrição expressa formas legítimas e adequadas de produção científica: temáticas prediletas, teorias de base, autores e linhas de pesquisa, por exemplo. Segundo esse autor, as convenções apresentadas acabam por demarcar territórios específicos, tanto no campo intelectual mais amplo quanto em campo intelectual restrito.

Sabe-se que a última palavra relacionada ao processo de publicação é do editor do periódico, porém não se pode negar a influência dos membros da equipe editorial na construção ideológica de ciência à medida que auxiliam na construção da política do periódico, além da seleção e opinião sobre artigos submetidos à avaliação. Em Chauí (2001), a dominação e poder são concepções atreladas à linguagem e estão indissociadas da vida social - neste sentido a política editorial reflete uma concepção ideológica de ciência.

Cabe relatar que a existência de uma concepção político-ideológica sobre o material submetido, bem como sobre todas as etapas do processo editorial, não desconstituem a cientificidade do periódico. Tal cientificidade resulta de um processo sistematizado e criterioso a partir do qual os estudos são elaborados. 


\subsection{Estrutura editorial e competências das subequipes de um periódico científico}

A equipe editorial do periódico científico é formada por um grupo de pesquisadores responsáveis por constituir ideias e tendências dominantes acerca da produção científica, bem como pela elaboração das etapas do processo de avaliação dessa produção. O processo de avaliação do material produzido, geralmente em forma de artigo, julga a consistência científica, a utilidade e a relevância social que determinam a qualidade necessária à publicação - todo esse material é parte da política editorial do periódico.

Trzesniak (2009) relata sobre riscos e potenciais prejuízos decorrentes da ação de um(a) único(a) pesquisador(a) como responsável por um periódico científico, uma vez que o editor já controla os acessos ao periódico (gatekeeper). Se não há uma a política editorial construída a partir da opinião dos membros de seu conselho, o periódico torna-se imposição de um modelo de pensamento fundado na opinião de um indivíduo e da sua forma de conceber ciência, criando viés e estereótipos científicos - acredita-se que tais riscos são atenuados ou refreados com a estruturação de uma equipe editorial.

Miranda e Pereira (1996) e Sandes-Guimarães e Diniz (2014) evidenciam a figura do editor como representação central no processo de comunicação científica, sendo o responsável pela primeira avaliação acerca do material que fará parte do processo de avaliação. Todavia tais autores destacam que o editor não é um livre empreendedor e precisa ser assessorado por seus pares enquanto membros do conselho editorial.

Tobochnik (2008) ressalta quão determinante é o papel do editor de um periódico, visto que todo conteúdo disponibilizado ao público depende, prioritariamente, da análise documental que ele realiza (desk review). Nesta concepção, o editor torna-se o mentor (guide keeper) do processo editorial - mesmo antes da avaliação dos pareceristas, o editor pode julgar e excluir o material submetido. Geralmente, a originalidade e a relevância do artigo para a área de atuação do periódico, a qualidade da linguagem, as regras de formatação/apresentação geral e demais aspectos da política editorial são ponderados pelo editor.

O papel do editor científico é proeminente e vai além dos atos burocrático-administrativos; sua função é acadêmico-científica. O exame das críticas e das observações que fundamentam o parecer dos avaliadores e a sua própria opinião acerca da produção submetida são essenciais ao processo editorial científico (Vasconcelos, 2017). A equipe editorial, por sua vez, constitui-se de indivíduos que se dispõe a contribuir com o progresso do acervo de conhecimentos humanos, garantindo o fluxo científico (Rodrigues et al., 2015).

A Associação Nacional de Pós-Graduação e Pesquisa em Administração (Anpad, 2010) e a NBR 6021 (2003) apresentam a estrutura editorial do periódico científico, geralmente, constituída por: editor/ editor-chefe/editor-geral - representação máxima do periódico; conselho editorial/conselho ou comitê de política editorial - responsável pela conjuntura política do periódico; comissão editorial, técnica ou científica - responsáveis pela seleção dos textos que se enquadram na política editorial.

As especificidades das subequipes editoriais elucidam sobre o funcionamento e delimitam o poder exercido pelos membros, evidenciando responsabilidades atribuídas a cada grupo. Os membros da equipe editorial podem exercer diferentes funções no periódico (Trzesniak, 2009); entende-se que a segregação de funções propicia qualidade aos trabalhos desenvolvidos pela equipe, tanto no que diz respeito à análise técnico-científica quanto às questões éticas.

O conselho editorial, conselho de política editorial ou comitê de política editorial, é formado que converge forças/potencialidades capazes de solidificar e perpetuar as atividades de um periódico científico (Trzesniak, 2009). Para além do cumprimento da obrigatoriedade normativa, esse conselho representa a ordenação das visões e experiências responsáveis pela essência ideológica do periódico. Conforme o mesmo autor, o conselho editorial deve ser constituído por pesquisadores que representem: entidades de retaguarda, áreas profissionais, instituições de pesquisa, órgãos de fomento e outras que se fizerem convenientes. É imprescindível que o periódico tenha uma retaguarda que confira respaldo intelectual para a continuidade das suas atividades, não apenas pela influência nominal ou financeira - o respaldo intelectual gera criticidade para percepção de pesquisas úteis. 
Em relação aos editores associados, Trzesniak (2009) considera ser preferível que tais conselheiros pertençam a instituições distintas daquela a que o periódico científico está vinculado. Trata-se de um grupo de conselheiros colaboram por meio de atividades editoriais, participando do processo de avaliação dos artigos, indicando avaliadores e verificando o texto final. Esse grupo também se envolve no processo de aceite do artigo e, por conseguinte, sua publicação, a designação do editor associado é feita por linha de pesquisa.

O corpo editorial é um colegiado multi-institucional composto de especialistas vinculados às áreas do saber a que o periódico se dedica, distribuídos tanto científica quanto geograficamente (Anpad, 2010 e Trzesniak, 2009). É importante ressaltar que o corpo editorial não tem influência direta sobre a produção do conhecimento, seus componentes são conselheiros do editor e oferecem sua parcela de contribuição de maneira individualizada, quando consultados - pessoas que têm poder de influenciar na opinião do editor.

\section{Metodologia}

De acordo com a abordagem de investigação, tem-se uma pesquisa, fundamentalmente, qualitativa, alicerçada na análise de conteúdo de Bardin (2016) que se ancorou na estatística básica (percentuais) para interpretação na análise de conteúdo e na construção de redes do software UCINET 6.

A abordagem qualitativa se caracteriza por entender, descrever e explicar os fenômenos sociais de maneiras distintas por meio da análise de experiências individuais e grupais, exame de interações e comunicações e da investigação de documentos (Flick, 2009). Por meio da pesquisa qualitativa, busca-se, na profundidade das relações sociais, o que está implícito. Já a análise de conteúdo se constitui em técnicas sistemáticas de análise das comunicações, objetivando a descrição do conteúdo das mensagens para obtenção de inferências relativas às condições de produção - tal inferência recorre a indicadores (quantitativos ou não) e sua execução se dá por meio de três etapas: pré-análise, exploração do material e tratamento dos resultados obtidos Bardin (2016).

A pré-análise, primeira etapa, se constitui na fase de organização do que busca operacionalizar e sistematizar as ideias e conduzir um esquema preciso do desenvolvimento das operações sucessivas - escolha dos documentos a serem analisados; formulação das hipóteses e dos objetivos e elaboração de indicadores que sustentam a interpretação final - nesta pesquisa não houve formulação de hipóteses.

São tarefas realizadas na pré-análise: leitura flutuante, escolha dos documentos, formulação de objetivos, seleção do corpus em análise e elaboração de indicadores. Realizou-se a leitura flutuante na página do periódico em análise: Revista Contabilidade e Finanças (RC\&F), vinculada ao Programa de Pós-graduação em Controladoria e Contabilidade da Universidade de São Paulo (PPGCC/USP). Acredita-se que esse periódico exerce significativa influência ideológica por ter o maior fator impacto da área contábil no Brasil, conforme Aragão, Oliveira e Lima (2013). Os autores optaram por examinar a política editorial da RC\&F, tomando como corpus de análise a missão, os objetivos, o escopo e as linhas de pesquisa desse referido periódico. A escolha do corpus se deu em função da representatividade deles para delimitação das características do material a ser submetido à RC\&F.

A exploração do material consiste em procedimentos aplicados manualmente ou por meio do computador com objetivo de obter as informações necessárias ao tratamento e interpretação dos resultados obtidos Bardin (2016). Nesta investigação, essa segunda etapa - exploração - se iniciou no recorte do enunciado a ser analisado. O recorte semântico foi determinado em função da unidade de registro substantivos, os quais se referem à produção científica submetida ao processo de avaliação do periódico, a saber: "produção científica", "conhecimento", "temas", "pesquisa", "artigos", "trabalhos", "resenhas", "pensatas", "notas bibliográficas" e "documentos". Em seguida, recortou-se semanticamente a unidade de registro adjetivos, ou palavras adjetivadas. Essas unidades se referem aos substantivos detectados anteriormente a fim de quantificá-los e interpretá-los - exploração do material por decomposição e enumeração; ele foi realizado com os verbos. 
Bardin (2016) afirma que os dados brutos são tratados de maneira que construam significados. Nesta investigação, a percentagem foi utilizada para quantificar o número de unidades de registro (substantivos e adjetivos) que aparecem no texto, bem como o número de substantivos utilizados como sinônimo ao referir-se ao material a ser submetido ao periódico. As etapas da análise de conteúdo, anteriormente descritas, revelam a sistematização da técnica de análise categórica política editorial da RC\&F.

A abordagem quantitativa revela o uso da estatística como apoio à interpretação - conforme descrito anteriormente - tanto para a frequência de palavras quanto para a análise composição da equipe editorial e a identificação das entidades das quais essa equipe fez/faz parte.

A descrição da equipe editorial da RC\&F se deu por meio da obtenção de informações fundamentadas no currículo dos seus membros (lattes para brasileiros e vitae para estrangeiros) e nas informações disponíveis no site da RC\&F, a saber: identificação dos conselheiros, e respectivas funções no periódico; vínculo dos conselheiros com a USP; vínculo dos conselheiros com outras IES brasileiras e país de IES internacional, quando havia vínculo. Estas informações foram tabuladas no software Excel 2007 e em seguida importadas para o software UCINET 6 for Windows. Após a tabulação, uma rede foi construída, pelo software UCINET 6, evidenciando a relação entre as categorias:"pesquisadores", "funções no periódico" e "IES de vínculo", cuja interpretação se deu por meio de valores relativos.

Por fim, realizou-se a análise do currículo dos conselheiros (lattes quando brasileiro e vitae quando estrangeiro) para identificar vínculos, atuais ou anteriores, com entidades de educação, pesquisa e atividades técnicas. Entende-se que esses vínculos influenciam a forma de conceber ciência e se refletem por meio deles nas ideologias da RC\&F.

\subsection{Revista Contabilidade e Finanças: ambiente de investigação}

A Revista Contabilidade \& Finanças (RC\&F) é um periódico do Departamento de Contabilidade e Atuária da Faculdade de Economia Administração e Contabilidade da Universidade de São Paulo (FEA/ USP), que conta com suporte financeiro Capes, do Conselho Nacional de Desenvolvimento Científico e Tecnológico (CNPq), Fundação Instituto de Pesquisas Contábeis, Atuariais e Financeiras (Fipecafi) e Programa de Apoio às Publicações Científicas Periódicas da USP (SIBi). Atualmente, a RC\&F tem favorecido a discussões e troca de experiências entre pesquisadores nacionais e internacionais de diversas linhas de pesquisa e áreas do conhecimento.

Quadrimestral e gratuita, a RC\&F foi inspirada num modelo de periódico francês e denominada, inicialmente, como Caderno de Estudos. Atualmente a revista é indexada a seguintes bases: Scientific Electronic Library Online (SciELO), EBSCO Publishing, ProQuest, Base Atena, Gale - Cengage Learning, Red de Revistas Científicas de América Latina, el Caribe, España y Portugal (Redalyc), Scientific Periodicals Electronic Library (SPELL) e Sumários de Revistas Brasileiras (Sumários) (RC\&F, 2015). A indexação a essas bases favorece a ressonância do conteúdo científico disponibilizado pela RC\&F, tornando-a um veículo de expressivo significado na condução e disseminação de estudos desenvolvidos na área contábil e, por conseguinte, na forma de fazer e pensar a pesquisa, principalmente no Brasil.

Dados coletados no site da Capes, em 2015, atestaram que, na Avaliação Trienal Capes 2013, a $\mathrm{RC} \& \mathrm{~F}$ recebeu o conceito A2. No site da revista consta que esse conceito é fruto de um esforço iniciado há 25 anos, todavia que a nota do órgão regulador não é o centro de sua preocupação e, sim, a divulgação de conhecimento relevante. Para atrair pesquisadores, a RC\&F mantém: regulamento formalizado e forte estrutura de governança; pluralismo ontológico e epistemológico; publicação em português e inglês ou espanhol e inglês; pagamento de custos de tradução dos trabalhos aceitos; indexações eficientes fomentando maior oportunidade de citação; fontes de financiamentos adicionais à Fipecafi, no Sistema Universitário de Bibliotecas (SIBI) e Conselho Nacional de Desenvolvimento Científico e Tecnológico (CNPq); incentivo a pesquisas que se relacionem com o escopo da Revista; profissionalização da estrutura de apoio interna e externa e comunicação tempestiva com autores, leitores e revisores. 


\section{Análise de Resultados}

Nesta seção estão dispostas as informações obtidas, as quais refletem o resultado do estudo. Buscou-se conhecer a concepção de produção científica representada por meio da política da Revista Contabilidade e Finanças (RC\&F). Tais informações estão dispostas nesta seção de maneira a garantir coerência e clareza à discussão apresentada.

\subsection{Composição da equipe editorial}

A equipe editorial da RC\&F é constituída por: editor-chefe, conselho editorial, editores associados e pelo corpo editorial científico - estrutura apresentada no site da revista que conformidade com a ABNT (2003) e o Anpad (2010). Em Trzesniak (2009), a equipe editorial, que possui de 20 a 35 membros e entre dois e quatro editores associados, consegue atender a um contingente de 100 submissões deferidas anualmente. Informações no site da RC\&F evidenciam que em 2014 foram deferidas 50 submissões, e a equipe editorial era composta por 34 membros - número superior àquele considerado como ideal pela literatura.

A Figura 1 revela que a RC\&F conta com 32 membros, dos quais seis são editores associados. 53\% dos membros do conselho editorial são da USP. Nota-se que $29 \%$ dos membros dessa equipe são exclusivos do conselho editorial - todos oriundos da USP - e 47\% exclusivos do corpo editorial científico. O percentual de $29 \%$ atrelado à discussão apresentada na seção anterior, permitem inferir que: as decisões são representativas de uma deliberação do grupo. Contrariamente, o corpo editorial científico trabalha individualmente, quando consultado, ambos os grupos representam minoria em termos de influência ideológica. Isto acontece porque entende-se que, em quaisquer das situações, os membros "exclusivos" de cada um desses grupos têm menos força participativa: os $29 \%$, porque têm participação diluída; e os $47 \%$, por ter participação esporádica. Por esse motivo, não serão feitos maiores comentários sobre o perfil desses conselheiros.

Verificou-se o perfil dos conselheiros que guardam significativa força participativa e, por conseguinte, influência ideológica no periódico, bem como as relações institucionais estabelecidas por eles. Segundo Koch (1999, p. 19), "como ser dotado de razão e vontade, o homem, constantemente avalia, julga, critica, isto é, forma juízo de valor". Acredita-se que isso influencia direta e/ou indiretamente na produção científica divulgada, já que a ideologia dominante é constituída pela opinião desse grupo.

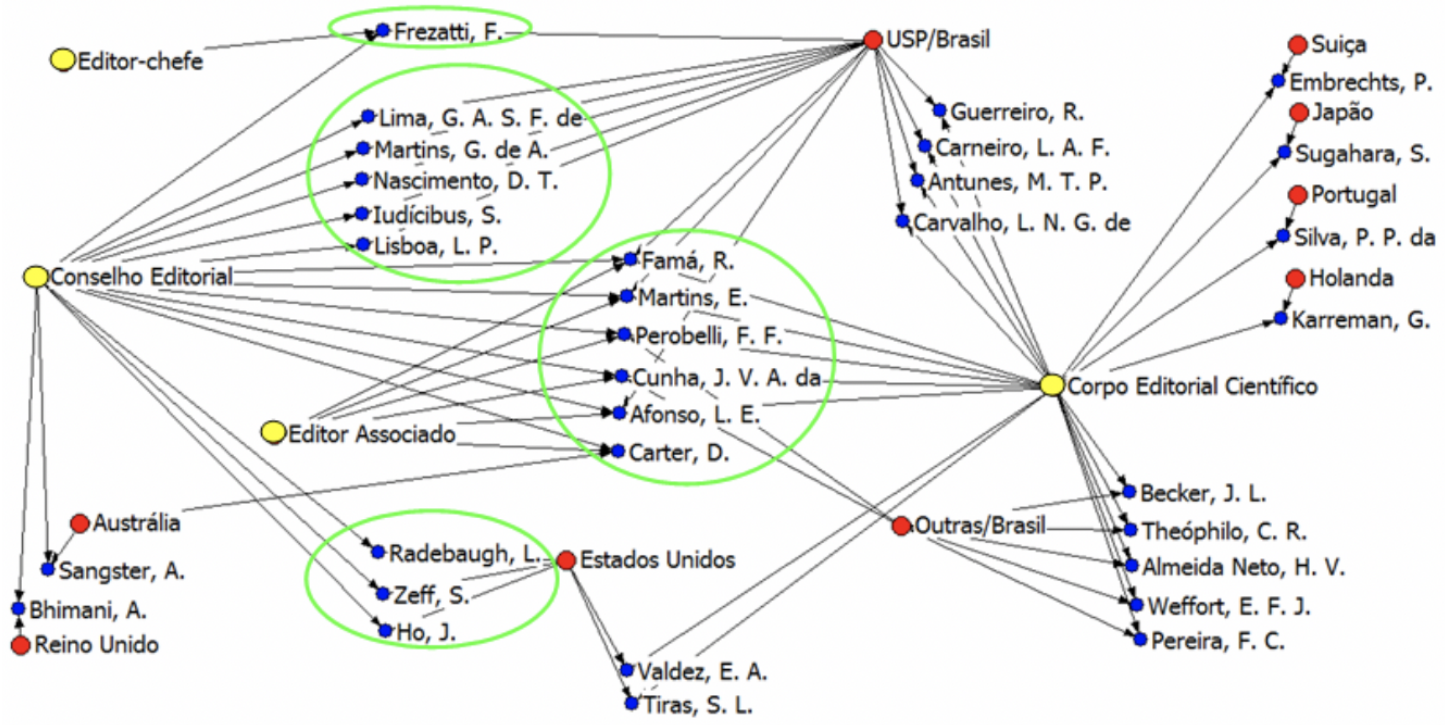

Fonte: dados da pesquisa (2015)

Figura 1. Equipe Editorial da RC\&F/2015: pesquisadores, suas funções e país da IES de vínculo 
De acordo com a Figura 1, tem-se que aproximadamente 22\% do colegiado que constitui a Equipe Editorial da RC\&F exercem duas ou mais funções. Os pesquisadores Famá, R.; Martins, E.; Perobelli, F. F.; Cunha, J. V. A. da; Afonso, L. E. e Carter, D. se destacam no contexto por fazerem parte de núcleo que atua diretamente sobre a Política Editorial e sobre a produção científica em avaliação exercendo as funções de Conselho Editorial e Editor Associado, respectivamente. Isso revela a potencialidade de ingerência (poder de influência ideológica) que eles têm sobre a revista em função de suas competências - seja no tocante à política editorial, seja na produção propriamente dita ou em situações específicas, quando chamados a atuar como corpo científico. Destaca-se, porém, que essa influência não é hierarquicamente superior ao poder de decisão decorrente da função de editor-chefe do periódico, exercida por Frezatti, F.

Ao considerar os países de origem das IES a que se vinculam os membros da Equipe Editorial da RC\&F (Figura 1), percebe-se que dentre 17 membros que compõem o Conselho Editorial há uma prevalência de brasileiros oriundos da USP (53\%) e de estrangeiros, vinculados a instituições sediadas nos Estados Unidos (18\%). Infere-se que as Políticas Editoriais da RC\&F tendem a ser representativas desses centros no que diz respeito à concepção de ciência - tanto na ontologia firmada por meio das linhas de pesquisa, quanto nas temáticas, teorias, metodologias e maneira de expor reflexões e críticas.

A prevalência de pesquisadores da FEA/USP no Conselho Editorial da RC\&F (53\%) não nos causa estranheza, afinal este periódico é vinculado ao Departamento de Contabilidade e Atuária da FEA/USP, tendo o chefe desse departamento como seu presidente. À luz da TRS, discutida no referencial teórico, pode-se inferir que os mecanismos cognitivos envolvidos no processo de representação do discurso científico, da concepção de qualidade e de estrutura da produção científica da comunidade FEA/USP, torna-se dominante no processo de geração e transformação de saberes, influenciando dialeticamente o saber cotidiano - interação entre o universo reificado e o universo consensual que integram os sistemas de valores dos sujeitos.

Entende-se que os princípios essenciais do periódico (missão, objetivos, público-alvo...), a sua estrutura e a sua linha editorial, bem como suas diretrizes de submissão e os aspectos éticos observados, são elaborados pelo Conselho Editorial atribuindo ao periódico uma "personalidade científica". Trzesniak (2009) considera que vínculos institucionais estabelecidos por um periódico científico podem assegurar a continuidade das atividades que este realiza - fator significativo para consolidar os elos e estreitar a comunicação entre academia e sociedade.

Por sua vez, os Editores Associados da RC\&F possuem graduação nas áreas de Contabilidade, Administração e Economia, áreas afins, além de Direito e Engenharia da Produção. Esses membros se dedicam exclusivamente a uma linha de pesquisa e, de acordo com o Curriculum Vitae (CV) de cada um, possuem experiência acadêmica e técnica nessas áreas. No que se refere à formação acadêmica desses pesquisadores, percebe-se que a USP e a University of Illinois e a Harvard Business School são instituições citadas em pelo menos dois CVs, seja em cursos de graduação, pós-doutorado ou formação complementar. Destaca-se que, apesar de não haver incoerência na composição dos Editores Associados, a configuração da RC\&F não atende ao que Trzesniak (2009) estabelece como preferencial - conselheiros que pertençam à instituição diferente daquela a que a RC\&F está vinculada.

É relevante destacar que, segundo CV, tanto os Editores Associados quanto o Editor-chefe (com atribuições técnicas e científicas) participam ou participaram de entidades de destaque e ingerência no cenário nacional da contabilidade - em alguns casos, essa participação se deu pelo exercício de funções como presidência e diretoria. No âmbito nacional, são exemplos de entidade a Comissão de Valores Mobiliários (CVM), Conselho Nacional de Desenvolvimento Científico e Tecnológico (CNPq), Coordenação de Aperfeiçoamento de Pessoal de Nível Superior (Capes), Conselho Federal de Contabilidade (CFC), Sociedade Brasileira de Finanças (SBFin), Banco Central do Brasil (Bacen), Comitê de Pronunciamentos Contábeis (CPC), Instituto dos Auditores Independentes do Brasil (Ibracon), Associação Nacional dos Executivos de Finanças, Administração e Contabilidade (Anefac), Associação Nacional de Pós-Graduação e Pesquisa em Administração (Anpad), Fundação Instituto de Pesquisas Contábeis Atuariais e Financeiras (Fipecafi) dentre outros(as). No âmbito internacional, têm-se a American Accounting Association (AAA), European Accounting Association (EAA), International Association for Accounting Education and Research (IAAER) e a International Actuarial Association (IAA). 
Além de formativa, a experiência e relações dos conselheiros em entidades ligadas à educação, à pesquisa e a atividade técnica promovem a integração academia-sociedade, oportunizando o estabelecimento de diálogos entre pesquisadores brasileiros e pesquisadores internacionais - esse fato acaba por refletir na demarcação científica, que, segundo Targino (2010), não segue a parâmetros de universalidade em função das influências de critérios externos, não especificados, os quais impactam na avaliação e na opinião dominante por autoridade científica. Desta forma, considera-se que essas instituições guardam significativa influência na maneira como os conselheiros da RC\&F percebem a potencial utilidade, a relevância e as contribuições dos artigos científicos submetidos. Trzesniak (2009) já expunha quão positivo é esse aspecto para a continuidade do periódico - a Capes, o CNPq e Fipecafi, por exemplo, são patrocinadores da RC\&F.

\subsection{Análise da política editorial: missão e objetivos Revista Contabilidade \& Finanças}

A missão e os objetivos do periódico retratam os interesses da revista, no caso da RC\&F a missão e os objetivos apresentados a seguir atendem às orientações do Manual de Boas Práticas de Pesquisa da Anpad (2010):

\begin{tabular}{|c|c|c|}
\hline Missão & Objetivos & Equipe Editorial \\
\hline $\begin{array}{l}\text { A Revista Contabilidade \& Finanças (RC\&F) } \\
\text { tem como missão a divulgação de produção } \\
\text { científica inédita e relevante na área de } \\
\text { Contabilidade, Controladoria, Atuária } \\
\text { e Finanças, produzida por professores, } \\
\text { pesquisadores, alunos e profissionais } \\
\text { do Brasil e do exterior, selecionada } \\
\text { exclusivamente com base em qualidade e } \\
\text { efetiva contribuição para o desenvolvimento } \\
\text { do conhecimento científico nesses campos. }\end{array}$ & $\begin{array}{l}\text { - Disseminar conhecimento relevante } \\
\text { nas áreas de Contabilidade, } \\
\text { Controladoria, Atuária e Finanças; } \\
\text { Instigar e provocar reflexões sobre } \\
\text { temas de relevância para a área, } \\
\text { comunidade acadêmica e sociedade; } \\
\text { - Ter reconhecimento nacional e } \\
\text { internacional como veículo de } \\
\text { comunicação de pesquisas. }\end{array}$ & $\begin{array}{ll}\text { - } & \text { Editor Chefe; } \\
\text { - } & \text { Conselho Editorial; } \\
\text { - } & \text { Editores Associados; } \\
\text { - } & \text { Corpo Editorial Científico. }\end{array}$ \\
\hline
\end{tabular}

Fonte: RC\&F (2015)

Quadro 1. Missão, objetivos e composição da equipe editorial da Revista Contabilidade e Finanças

O discurso proferido na missão da RC\&F expressa interesse em publicar produção inédita e relevante, que traga efetiva contribuição para o desenvolvimento científico na área contábil, de autoria de "professores, pesquisadores, alunos e profissionais". Pelo expresso no texto, compreende-se que o periódico tenciona por produções decorrentes de indivíduos que se enquadram tanto no contexto técnico ou quanto acadêmico, incluso que a descrição tem a intenção de mostrar a abertura que o periódico oferece a diferentes públicos a fim de se aproximar dos seus potenciais autores. Todavia, na tipologia utilizada para se referir aos potenciais autores do periódico, evidencia-se o distanciamento entre os interessados na produção da área uma vez que os termos "professores" e "pesquisadores", "profissionais" são usados com intenções semânticas distintas. Concebe-se a ideia de um professor que não pode ser pesquisador, bem como de um professor e pesquisador que não podem ser um profissional técnico; o contrário é verdadeiro para ambos os casos. Além do evidente hiato existente quando se faz referência à academia e à sociedade, ainda que de maneira inconsciente, percebe-se também que o texto oculta o termo técnico para se referir ao profissional que não possui vínculo com a academia - a adição do termo a esta análise se dá porque parece que essa seria a intenção do discurso. 
Outro aspecto que merece atenção é a expressão "do Brasil e do exterior" para fazer referência aos potenciais autores do periódico. Como a possibilidade de estudos internacionais abordarem temáticas de interesse específico do Brasil, pode-se compreender que o periódico se interessa também por assuntos de interesse global - este fato revela um dos elementos observados ao expressar o interesse por "produção inédita e relevante". Se, por um lado, pensa-se que a abertura a produção internacional é uma tentativa de aproximação a realidades outras que podem favorecer ao aprendizado e ao amadurecimento das discussões, por outro, essa abertura requer uma atenção redobrada quando da seleção dos artigos para o processo de avaliação. Acredita-se que o estabelecimento do diálogo científico seja produtivo se artigos apresentarem discussões relativas a temáticas e problemas que, pelo menos, tangenciem aqueles enfrentados pela contabilidade de um país em desenvolvimento como o Brasil. Este cuidado parece manifesto quando no texto da missão surge a expressão "selecionada exclusivamente com base em qualidade e efetiva contribuição para o desenvolvimento do conhecimento científico...”.

Ademais, entende-se que a qualificação "relevante" possui centralidade. Esse termo é retomado nos objetivos por meio da repetição do item lexical "relevante" e por meio de uma palavra do mesmo campo semântico "relevância". Pode-se, inclusive, inferir que a missão da RC\&F se apropria do termo "relevância" como equivalente à expressão "efetiva contribuição" e a palavra "qualidade", visto que essas são critérios exclusivos e balizadores dos aceites concedidos por esse periódico. Porém, enquanto a expressão "efetiva contribuição" remete à ideia concreta de utilidade da pesquisa, a julgada "qualidade" não consegue alcançar o mesmo êxito em função da multiplicidade de sentidos que pode gerar - não há qualquer menção sobre a que vem dizer essa pesquisa de qualidade.

Cabe observar ainda que, embora os termos "relevante" e "relevância" apareçam em dois dos três objetivos, e a definição do que é "relevante", compete aos avaliadores do periódico. O que tem mais peso é "ser relevante", característica de difícil definição, inclusive porque essa relevância (que pode ser percebida pela ressonância da pesquisa, por exemplo) só se materializará de fato após tornar o artigo produzido de conhecimento público e, não, no momento da seleção. Assim, como todos os artigos publicados na RC\&F têm o atributo "relevância", há uma tendência de que os pesquisadores possam tomá-los como parâmetro para novas produções, estabelecendo um efeito "propagandístico" - o discurso tanto é influenciado pelo contexto social quanto tem poder para influenciá-lo. Assim, os artigos publicados pela RC\&F têm poder para captar, modificar e propor realidade - neste caso, a replicação dos artigos é a materialização dessa influência discursiva. Conforme explanou-se no referencial teórico, o periódico científico é lugar de veiculação de um discurso prescritivo.

O efeito "propagandístico" do periódico pode ser percebido pelo uso dos verbos divulgar e disseminar. Além da escolha desses dois verbos, há que se observar também a transformação da frase "Divulgação de produção científica relevante" para "Disseminar conhecimento relevante" desaparecendo o caráter inédito do conhecimento a ser divulgado. Ainda que se argumente que a palavra "inédita" está elíptica, o aparecimento do terceiro objetivo não relacionado diretamente à produção e, sim, relacionado à abrangência geográfica da disseminação pretendida é suficiente para amenizar tal argumento.

Apontando ao mesmo tempo para a divulgação e para a relevância, não é de se estranhar que vá se desencadear a elaboração de replicações. Como "o mundo da pesquisa envolve a manipulação e o poder do mainstream" (Frezatti et al., 2009, p. 7), entende-se que, por vezes, as replicações são realizadas como estratégia para a aceitação e, conseguinte, publicação do artigo mantendo um perigoso ciclo de inércia e/ ou atrofia do conhecimento científico gerado, fruto da produção do grupo de indivíduos que seguem regras gerais da política com fins produtivistas. Outro aspecto que merece atenção é a expressão "reconhecimento nacional e internacional" citada no terceiro objetivo, de maneira a desalinhá-lo da discussão sobre produção de conhecimento, dado que respeito à abrangência geográfica pretendida - uma preocupação de alcançar status além das fronteiras do país. Isso permite pensar que as temáticas serão escolhidas com a expectativa de atender também a um público estrangeiro, e podem trazer, por vezes, discussões de questionável "relevância" às organizações e a sociedade brasileira em geral. 


\subsection{Análise do texto referente ao escopo e linhas de pesquisa da RC\&F}

Ao considerar o que está expresso no escopo e linhas de pesquisa da RC\&F, os artigos submetidos a esse periódico científico devem observar o que está expresso no Quadro 2 a seguir:

\begin{tabular}{lll}
\hline \multicolumn{1}{c}{ Escopo } & \multicolumn{1}{c}{ Linhas de pesquisa } \\
\hline A RC\&F publica artigos inéditos de desenvolvimento teórico & . & Controladoria e contabilidade gerencial; \\
e trabalhos teórico-empíricos nas áreas de Contabilidade, & Contabilidade para usuários externos; \\
Controladoria, Atuária e Finanças. Aceita trabalhos de diferentes & - & $\begin{array}{l}\text { Mercados: financeiro, de crédito e de capitais; } \\
\text { paradigmas e metodologias, desde que sejam consistentes e }\end{array}$ \\
relevantes para o desenvolvimento das áreas. Além de artigos, & Educação e pesquisa em contabilidade, \\
foco principal do periódico, publica resenhas, comunicações, notas & controladoria, atuária e finanças; \\
bibliográficas, pensatas e documentos que possam contribuir para & - & Atuária; \\
a comunicação de novos conhecimentos para a comunidade. & Temas emergentes em Contabilidade, \\
\hline
\end{tabular}

Fonte: RC\&F (2015).

Quadro 2. Escopo e linhas de pesquisa da Revista Contabilidade e Finanças

O vocabulário utilizado para a descrição do escopo da revista RC\&F apresenta na primeira frase o atributo "inéditos" fazendo alusão ao termo "artigos"; em seguida, a conjunção aditiva "e" que une as expressões "artigo inéditos de desenvolvimento teórico" a expressão "trabalhos teórico-empíricos". Dito dessa forma, entende-se que os artigos precisam ser inéditos e teóricos; já os trabalhos requerem o atributo teórico-empírico, ainda que na prática a RC\&F considere o ineditismo como condição necessária para a publicação de artigo. O sentido da frase revela a descrença de que trabalhos que envolvem aspectos pragmáticos não podem ser inéditos. Além disso, há subjetividade acerca do formato dos trabalhos teórico-empíricos suscetíveis de apresentação, já que o termo "trabalhos" é generalista. Ratifica-se essa interpretação quando na segunda frase do parágrafo na expressão "aceita trabalhos de diferentes paradigmas e metodologias".

Um outro fato que chama a atenção é o uso da expressão "desde que sejam consistentes e relevantes para o desenvolvimento das áreas". Entende-se que o vocábulo "consistentes" consegue delimitar sentido e refere-se à questão da cientificidade dos trabalhos. Já o vocábulo "relevantes" deixa mais uma vez diante de uma situação de subjetividade, vinculada ao processo de seleção dos trabalhos, e de forte impacto para a área de conhecimento - trata-se de um critério que determinará a essência do interesse científico das áreas de conhecimento contempladas pela revista (Contabilidade, Controladoria, Atuária e Finanças). Na última frase do parágrafo, tem-se que resenhas, comunicações, notas bibliográficas, pensatas e documentos podem vir a ser publicadas, desde que a RC\&F as compreenda como aporte de "novos conhecimentos para a comunidade". O termo "novo" pertence ao mesmo campo semântico do termo "inéditos" utilizado na primeira frase do parágrafo do escopo. Enquanto na primeira frase ele se referia a "artigos", nessa última ele se refere a "conhecimentos" propiciados pelos outros tipos de trabalhos que também são aceitos pela revista. Dessa maneira, tanto os artigos considerados "foco principal do periódico" quanto aqueles outros trabalhos citados anteriormente devem ser originais.

De acordo com a RC\&F (2015), este periódico publica, por ano, um artigo por autor - seja esse artigo uma produção individual ou em grupo - em atenção às boas práticas de pesquisa. Ainda segundo as normas desse periódico, quando a investigação trata sobre sistemas de mensuração, informação e apoio ao processo de planejamento e controle das instituições, ela é classificada na linha, "controladoria e contabilidade gerencial". Caso a discussão seja sobre aspectos de identificação, mensuração e divulgação da informação contábil, tem-se um estudo da linha "contabilidade para usuários externos". Se aborda aspectos conceituais e/ou empíricos de mercados, bem como sobre aplicação de recursos sob a ótica da performance empresarial passado e/ou projetada, vinculados à Contabilidade, o estudo é classificado na linha de "mercados: financeiro, de crédito e de capitais". 
Quando o trabalho traz aspectos relacionados ao processo de ensino-aprendizagem e da pesquisa contábil, o estudo pertence à linha de "educação e pesquisa em contabilidade, controladoria, atuária e finanças". Se a temática é sobre modelos, métodos, técnicas e instrumentos e construção de trabalhos científicos vinculados às Ciências Atuariais tem-se um estudo da linha "atuária". Consta no site da RC\&F (2015) a inserção de uma nova linha de pesquisa denominada "Temas emergentes em Contabilidade, Finanças e Atuária”, a qual abarca os denominados assuntos inovadores.

\section{Conclusões}

O objetivo desta pesquisa foi conhecer a concepção de pesquisa científica representada por meio da política e equipe editorial da Revista Contabilidade e Finanças (RC\&F).

Identificou-se que a RC\&F ampliou generosamente a sua capacidade de disseminação de pesquisas realizadas por pesquisadores nacionais (estudantes, profissionais técnicos e professores) e internacionais com o intuito de estreitar os laços entre academia e sociedade, bem como promover o diálogo com pares - esta interação consolidou o que a revista considera como produções que trazem "efetiva contribuição". De acordo com a concepção ideológica de pesquisa científica da RC\&F, essa efetiva contribuição está atrelada à "qualidade" e é requisito para que a produção científica seja considerada como "relevante".

Os atributos "qualidade" e "efetiva contribuição" são ponderados por meio da avaliação feita pelos Consultores Ad Hoc, todavia as minúcias a serem consideradas no processo de avaliação decorrem daqueles da concepção de pesquisa científica dos que têm maior ingerência sobre o conhecimento disseminado pelo periódico: o Editor e os Editores Associados.

O Editor e os Editores Associados da RC\&F são influenciados pela concepção de mundo das instituições de educação e pesquisa dos quais fazem ou fizeram parte e do conhecimento técnico construído a partir do trabalho que realizam, destacando-se as concepções de ciência da USP, não só porque a revista pertence ao Departamento de Contabilidade da FEA/USP, mas porque 53\% da Equipe Editorial são vinculados ou são egressos da USP. Destaca-se ainda que $18 \%$ dos membros que fazem parte desta equipe representa influência ideológico-científica dos Estados Unidos - desconsideram-se, nesse último percentual, os membros brasileiros que possuem formação em IES americana.

Além das influências ideológicas citadas anteriormente, a concepção de ciência da RC\&F inferiu-se que a RC\&F também sobre influência de entidades como: Capes, Fipecafi, CFC, CVM, Anpad, AAA, IAAER, CNPq, Bacen, Ibracon, entre outras, de significativa representatividade no âmbito da pesquisa, educação e produção de conhecimento técnico nacional e internacional em decorrência da participação de seus membros nestas.

A Política Editorial do periódico também anuncia uma ideologia de "abertura ao pluralismo ontológico e epistemológico", aspectos salutares que permitem a inserção de pesquisas fundamentadas em diferenciadas formas de conceber e construir o conhecimento científico. Acredita-se que tal fato formaliza a abertura de espaço para discussões fundadas em olhares distintos sobre temáticas da área, apesar de notar-se que, comumente, há uma "pactuação tácita" por parte dos pesquisadores na forma de fazer ciência - entende-se que a subjetividade do termo "relevante" e "qualidade" pode conduzir a outros pesquisadores a se espelharem nos trabalhos publicados.

A referida "pactuação" pode acarretar na reprodução e atrofia de algumas discussões, isto porque, em função dela, os pesquisadores da área contábil podem produzir ciência norteada por metodologias e teorias ou temáticas que, por vezes, já não são capazes propiciar as desejadas "efetivas contribuições" - há preocupação com a aceitação de suas ideias na comunidade acadêmica e de não provocar incômodo/contraponto intelectual aos seus pares. A disseminação de investigações de relevância internacional, ideologia que também decorre da política da RC\&F, se tornará infrutífera se essas não forem capazes de materializar efetivas contribuições para a cultura escrita e para o desenvolvimento técnico da área contábil brasileira. 
A RC\&F tem por ideologia uma a produção científica baseada nos atributos de relevância, ou seja, que tem qualidade e propicia "efetiva contribuição", fortemente influenciados pela maneira de conceber ciência da USP, das entidades nacionais e internacionais anteriormente citadas e de IES dos EUA. Todavia esses atributos norteadores da concepção de ciência veiculada pela RC\&F podem gerar ruídos de comunicação em função da sua subjetividade. Esses podem acarretar um processo reprodução de temáticas, metodologias, teorias e estruturais em decorrência da busca por um modelo de produção científica relevante por pesquisadores que desejam publicar na RC\&F, fato explicado por meio da TRS, apesar de propagação da ideologia de "pluralidade ontológica e epistemológica".

Ao se considerarem os fundamentos da Teoria das Representações Sociais, pode-se entender que o estudo tem como limitação o fato de não contemplar análises sobre os Consultores Ad Hoc, de maneira complementar à análise realizada acerca dos membros do conselho editorial, isto porque tal análise poderia ratificar as influências ideológicas já evidenciadas e/ou indicar outras. Para futuras investigações, considera-se significante a apreciação da Política Editorial de outros periódicos da área contábil, bem como o exame do perfil dos membros que são Consultores $A d H o c$, a fim obter informações sobre as relações estabelecidas e, por conseguinte, identificar as concepções que emergem do discurso científico produzido pela contabilidade brasileira.

\section{Referências}

Associação Brasileira de Normas Técnicas. (2003). NBR 6021: Publicação periódica científica impressa. Rio de Janeiro.

Aragão, I. R. B. N. (2016). Hegemonia do discurso científico contábil no Brasil (Doctoral dissertation, Universidade de São Paulo).

Aragão, I. R. B. N., Oliveira, J. R. S. \& Lima, G. A. S. F. (2013). Ressonância de artigos e fator de impacto de periódicos brasileiros de contabilidade. Revista de Educação e Pesquisa em Contabilidade, 8(1). DOI: https://doi.org/10.17524/repec.v8i1.1011.

Associação Nacional de Pós-graduação e Pesquisa em Administração. (2010). Boas práticas da publicação Científica: um manual para autores, revisores, editores e integrantes de Corpos Editoriais. Retrieved from www.anpad.org.br/diversos/boas_praticas.pdf

Bardin, L. (2016). Análise de Conteúdo. São Paulo: Edições 70.

Belkin, N. J. (1980). Anomalous states of knowledge as basis for information retrieval. Canadian Journal of Information Science, 5, pp. 133-143.

Castedo, R. S. \& Gruszynski, A. C.. (2011). A produção editorial de revistas científicas on-line: uma análise de publicações brasileiras da área da Comunicação. Revista em Questão, 1(17), pp. 271-287.

Chauí, M. (2001). O que é ideologia. Rev. e ampl. São Paulo: Brasiliense.

Cordeiro, J. F. P. (2008). A produção em história da educação no Brasil em três periódicos: perspectivas comparadas. Recuperada em 10 de janeiro, 2016 de http://sbhe.org.br/novo/congressos/cbhe5/pdf/698.pdf.

Cunha, J. V. A. D., Cornachione Jr, E. B., \& Martins, G. D. A. (2008). Pós-graduação: o curso de doutorado em ciências contábeis da FEA/USP. Revista Contabilidade \& Finanças, 19(48), pp. 6-26.

Fiorin, J. L. (1993). Linguagem e ideologia. Editora Ática.

Flick, U. (2009). Desenho da pesquisa qualitativa. Porto Alegre: Artmed.

Frezatti, F., do Nascimento, A. R. \& Junqueira, E. (2009). Desenvolvimento da pesquisa em Contabilidade Gerencial: as restrições da abordagem monoparadigmática de Zimmerman. Revista Contabilidade \& Finanças, 20(49), pp. 6-24. 
Gomes, V. P. (2010). O Editor de Revista Científica: desafios da prática e da formação. Informação \& Informação, 1(15), pp. 147-172. doi: http://dx.doi.org/10.5433/1981-8920.2010v15n1p147

Gruszynski, A, C., Golin, C. \& Castedo, R. (2008). Produção editorial e comunicação científica: uma proposta para edição de revistas científicas. E-Compós, 11(2), pp. 1-17. doi: https://doi.org/10.30962/ ec.v11i 2.238

Jodelet, D. (1986). La representacion social: fenomenos, concepto y teoria. In Moscovici, S. (Ed.), Psicología social II (pp. 469-494). Barcelona: Ediciones Paidós.

Jodelet, D.(2001). Representações Sociais: um domínio em expansão. In: Jodelet, D. (Org.). As representações sociais, (pp. 17-44). Rio de Janeiro: EDUERJ.

Koch, I. G. V. Argumentação e linguagem. Cortez Editora, 1999.

Lane, S. T. M. (1984). A Psicologia social e uma nova concepção de homem para a Psicologia. In Lane, S. T. M. \& Codo, W. (Eds.), Psicologia social: o homem em movimento (pp. 10-19). São Paulo: Brasiliense.

Miranda, D. B. \& Pereira, M. N. F. (1996). O periódico científico como veículo de comunicação: uma revisão da literatura. Ciência da Informação, Brasília, 25, pp. 375-383.

Modesto, A. T. T. (2014). Linguagem, ideologia e preconceito linguístico na sociedade. Revela, 2(1), pp. 1-27.

Moscovici, S. (1978). A representação social da psicanálise: resultados da pesquisa de opinião e análise teórica. (A. Cabral, Trad.). Rio de Janeiro: Zahar. (Obra original publicada em 1961).

Moscovici, S., (2001). Das representações coletivas às representações sociais: elementos para uma história. İn: JODELET, Denise (Org.). As representações sociais (pp. 45-64). Rio de Janeiro: EDUERJ.

Moscovici, S. (2012). Representações sociais: investigações em psicologia social. (P. A. Guareschi, Trad.). Petrópolis: Vozes. (Obra original publicada em 1989).

Meadows, A. J. (1999). A comunicação científica. Brasília: Briquet de Lemos.

Morin, E. (2005). Ciência com consciência. (M. D. Alexandre, \& M. A. Dória, Trads.) Rio de Janeiro: Bertrand Brasil.

Paula, A. da S. de \&, Kodato, S. (2016). Psicologia Social e representações sociais: uma aproximação histórica. Revista de Psicologia da IMED. 8(2), pp. 200-207. doi: https://doi.org/10.18256/2175-5027/ psico-imed.v8n2p200-207

Rodrigues, R. S., Quartiero, E. \& Neubert, P. (2015). Periódicos Científicos Brasileiros indexados na Web Of Science e Scopus: estrutura editorial e elementos básicos. Informação \& Sociedade: Estudos, 25(2), pp. 117-138.

Sá, C. P.(1993). Representações sociais: o conceito e o estado atual da teoria. In: SPINK, Mary Jane (Org.). O conhecimento no cotidiano: as representações sociais na perspectiva da psicologia social. São Paulo: Brasiliense, pp. 19-45.

Sandes-Guimaraes, L. V. \& Diniz, E. H. (2014). Gestão de periódicos científicos: estudo de casos em revistas da área de Administração. Revista de Administração, 49(3), p. 449-461. doi: 10.5700/rausp1160

Santos Filho, G. M. dos (2016). A ciência é uma ideologia?. Intelligere, Revista de História Intelectual, 2(1), pp. 100-111. doi: https://doi.org/10.11606/issn.2447-9020.intelligere.2016.112277

Silva, E. A. da. (2017). Entre discursos e práticas: representações sociais de professores sobre a socialização na Educação Infantil. 2017. Dissertação de Mestrado em Educação, Universidade de Brasília (UnB), Brasília, DF, Brasil.

Targino, M. das G. (2000). Comunicação Científica: uma revisão de seus elementos básicos. Informação \& Sociedade: Estudos, 10(2), pp.37-85.

Tragino, M. das G. (2010). Orientador ou tutor é autor? Informação \& Informação, 15(1), pp. 145 - 156. doi: http://dx.doi.org/10.5433/1981-8920.2010v15n1espp145. 
Targino, M. C. (2016). Produção e comunicação científica como estratégias de formação profissional do cientista da informação. Ciências da Informação, 45(1), pp. 127-140.

Tobochnik, J. (2008). The art of doing. American Journal of Physics, 76(8), p. 701.

Trzesniak, P. (2009). A Estrutura editorial de um periódico científico. In Publicar em Psicologia: um Enfoque para a Revista Científica (pp. 87-102). São Paulo: Associação Brasileira de Editores Científicos de Psicologia; Instituto de Psicologia da Universidade de São Paulo.

Vasconcellos, V. G. (2017). Editorial: a função do periódico científico e do editor para a produção do conhecimento no Direito e nas ciências criminais. Revista Brasileira de Direito Processual Penal, 3(1), pp. 9-17.

Wurman, R. S. (1992). Ansiedade de informação. São Paulo: Cultura. Recuperado em 19 de junho, 2015, http://www.revistas.usp.br/rcf/about /history.. 